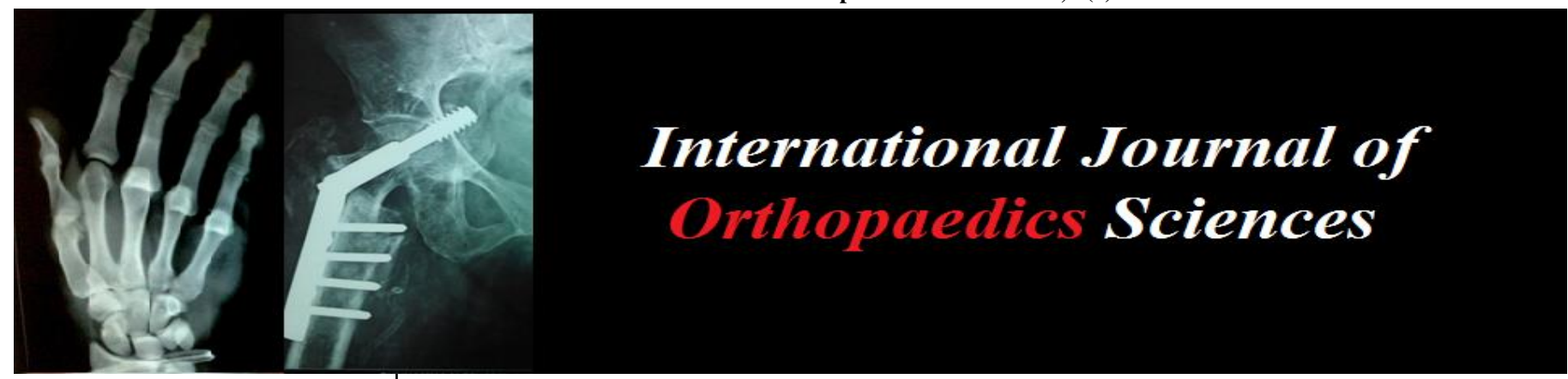

E-ISSN: 2395-1958

P-ISSN: 2706-6630

IJOS 2021; 7(1): 321-323

(C) 2021 IJOS

www.orthopaper.com

Received: 24-11-2020

Accepted: 26-12-2020

Dr. Gaurav Mehdiratta Consultant Orthopaedic Surgeon, Joint District Hospital

Manjhanpur, Kaushambi, Uttar

Pradesh, India
Corresponding Author: Dr. Gaurav Mehdiratta Consultant Orthopaedic Surgeon, Joint District Hospital Manjhanpur, Kaushambi, Uttar Pradesh, India

\section{Arthroscopic repair versus open surgical techniques for the management of recurrent anterior shoulder instability: A comparative study}

\section{Dr. Gaurav Mehdiratta}

DOI: https://doi.org/10.22271/ortho.2021.v7.i1f.2502

\section{Abstract}

Background: Surgical shoulder stabilization has been shown to reduce the risk of recurrence with some authors recommending intervention even after a single dislocation. The present study compared arthroscopic repair versus open surgical techniques for the management of recurrent anterior shoulder instability.

Materials \& Methods: 50 patients of anterior shoulder instability of both genders were divided into 2 groups of 25 each. Group I comprised of patients managed with arthroscopic method and group II with open surgery. Modified Rowe score and ASES (American Shoulder and Elbow Society) score were recorded.

Results: The mean ROWE pain score at 4 weeks was 3.0 and 3.4 in group I and II respectively, at 6 weeks was 5.4 and 5.0 in group I and II respectively, at 9 weeks was 10.2 and 5.8 in group I and II respectively and at 12 weeks was 10.1 and 9.2 in group I and II respectively. The mean ASES pain score at 4 weeks was 2.6 and 1.3 in group I and II respectively, at 6 weeks was 4.3 and 2.5 in group I and II respectively, at 9 weeks was 2.8 and 2.0 in group I and II respectively and at 12 weeks was 3.2 and 3.0 in group I and II respectively. The difference was non- significant $(P>0.05)$.

Conclusion: Both techniques were observed to be equally effective in the management of cases of recurrent anterior shoulder instability.

Keywords: anterior shoulder instability, ASES score, rowe score

\section{Introduction}

The shoulder is a ball and socket joint made up of the humeral head (ball) from the upper arm, and the glenoid (socket) from the shoulder blade (scapula) ${ }^{[1]}$. This allows to freely move arm in all directions. However, because it so mobile, it is also one of the most commonly dislocated joints in the human body. Dislocation occurs when the ball is wrenched out of its socket. The force required to do this can also tear or partially tear the muscles, ligaments and/or shoulder capsule surrounding the joint ${ }^{[2]}$. The shoulder can become dislocated during any significant injury where the force is great enough to overcome the stabilising structures of the shoulder joint. This can be from a fall, on the sporting field, or during a car accident. Occasionally it can occur with minimal force in someone with inherently lax joints. Recurrent shoulder dislocation is defined as more than or equal to three documented dislocations in a year ${ }^{[3]}$.

Surgical shoulder stabilization has been shown to reduce the risk of recurrence with some authors recommending intervention even after a single dislocation, though this remains controversial. Despite lower reported recurrent anterior instability with operative treatment, recurrence after primary stabilization surgery remains high in adolescents ${ }^{[4]}$. Studies looking specifically at adolescent patients have shown recurrence after primary stabilization surgery to range from 17 to $51 \%$, and rates for specific subpopulations, such as contact athletes or those with glenoid or bipolar bone loss, may be even higher. Thus, identifying risk factors for failure of primary stabilization surgery is of vital importance to choose the appropriate primary procedure or, when needed, address sources of possible failure in revision surgery ${ }^{[5]}$. The present study compared arthroscopic repair versus open surgical techniques for the management of recurrent anterior shoulder instability. 


\section{Materials \& Methods}

The present study comprised of 50 patients of anterior shoulder instability of both genders. All patients were informed regarding the study and their written consent was obtained.

Data pertaining to patients such as name, age, gender etc. was recorded. All patients were divided into 2 groups of 25 each. Group I comprised of patients managed with arthroscopic method and group II with open surgery. Modified Rowe score, ASES (American Shoulder and Elbow Society) score and Goniometer were recorded and compared between group I and II. Results thus achieved were statistically analysed. P value less than 0.05 was considered significant.

\section{Results}

Table 1: Distribution of patients

\begin{tabular}{|c|c|c|}
\hline Groups & Group I & Group II \\
\hline Method & Arthroscopic method & Open surgery \\
\hline M:F & $15: 10$ & $14: 11$ \\
\hline
\end{tabular}

Table I shows that group I had 15 males and 10 females and group II had 14 males and 11 females.

Table 2: Assessment of ROWE pain in both groups

\begin{tabular}{|c|c|c|c|}
\hline Duration (Weeks) & Group I & Group II & P value \\
\hline 4 & 3.0 & 3.4 & 0.91 \\
\hline 6 & 5.4 & 5.0 & 0.98 \\
\hline 9 & 10.2 & 5.8 & 0.02 \\
\hline 12 & 10.1 & 9.2 & 0.81 \\
\hline
\end{tabular}

Table II, graph I shows that mean ROWE pain score at 4 weeks was 3.0 and 3.4 in group I and II respectively, at 6 weeks was 5.4 and 5.0 in group I and II respectively, at 9 weeks was 10.2 and 5.8 in group I and II respectively and at 12 weeks was 10.1 and 9.2 in group I and II respectively. The difference was non- significant $(P>0.05)$.

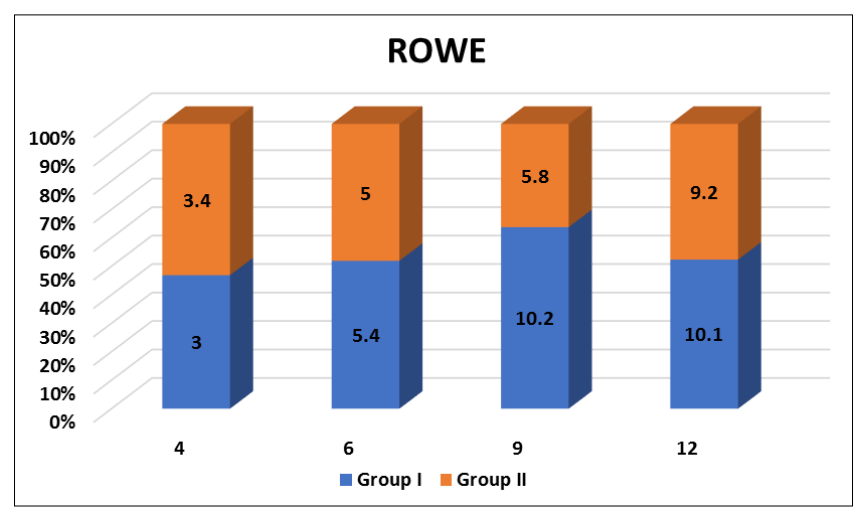

Graph 1: Assessment of ROWE pain in both groups

Table 3: Assessment of ASES pain in both groups

\begin{tabular}{|c|c|c|c|}
\hline Duration (Weeks) & Group I & Group II & P value \\
\hline 4 & 2.6 & 1.3 & 0.01 \\
\hline 6 & 4.3 & 2.5 & 0.03 \\
\hline 9 & 2.8 & 2.0 & 0.91 \\
\hline 12 & 3.2 & 3.0 & 0.94 \\
\hline
\end{tabular}

Table II, graph I shows that mean ASES pain score at 4 weeks was 2.6 and 1.3 in group I and II respectively, at 6 weeks was 4.3 and 2.5 in group I and II respectively, at 9 weeks was 2.8 and 2.0 in group I and II respectively and at 12 weeks was 3.2 and 3.0 in group I and II respectively. The difference was non- significant $(P>0.05)$.

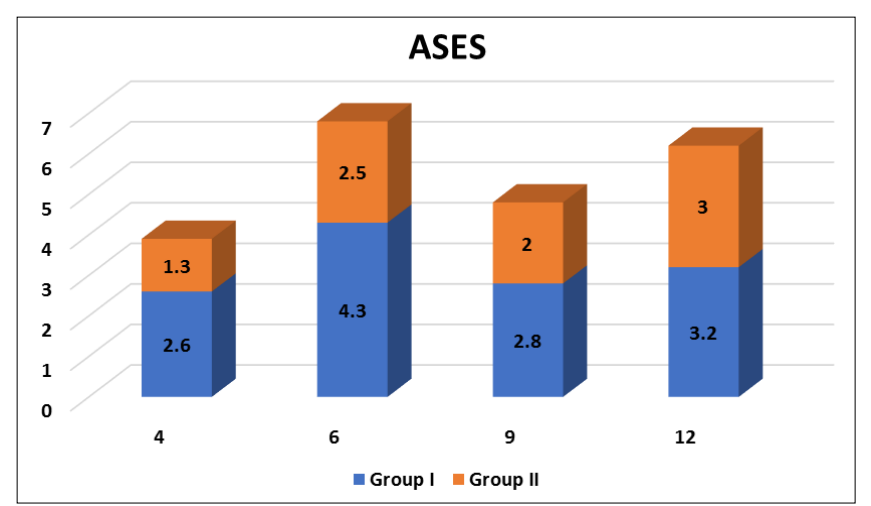

Graph 2: Assessment of ASES pain in both groups

\section{Discussion}

Shoulder instability in the pediatric population covers a spectrum of pathology including anterior, posterior, and multidirectional instability. Anterior instability represents the vast majority of shoulder instability in this population, and $19 \%$ of all anterior shoulder dislocations occur in patients between the ages of 15 and 19 years ${ }^{[6]}$. In patients age 18 and younger, males and patients greater than 14 years of age have the greatest risk of recurrent shoulder instability, while patients with open physes are less likely to see a recurrence. Estimates of recurrence in the older adolescents (14-18 years) with conservative management are as high as $92 \%{ }^{[7]}$.

Successful treatment of anterior instability of the shoulder requires a balance between restoring joint stability and minimizing loss of glenohumeral motion. The choice of treatment should be individualized on the basis of the patient's occupation and level of participation in sports, as well as on the degree of instability of the shoulder ${ }^{[8]}$. Despite discussions to the contrary, there is no single "essential lesion," as proposed by Bankart, that is responsible for recurrent anterior shoulder instability, although the Bankart lesion is by far the most important. The choice of operative treatment must be tailored to correct the abnormality that is identified at the time of surgery ${ }^{[9]}$. A variety of promising arthroscopic techniques have been developed for the treatment of anterior shoulder instability; however, open stabilization remains the standard, especially for severe instabilities, revision procedures, and for athletes who participate in contact sports. This article will review the open surgical techniques used for treatment of anterior instability of the shoulder. Both current and historical operations will be discussed. Regardless of which procedure is chosen by a surgeon, the treatment should follow the guidelines taught by Rowe: anatomic dissection at the time of surgery, identification and repair of the lesions responsible for the instability, returning tissues to their anatomic locations, and early postoperative range of motion. By following these guidelines, the results of treatment of anterior instability of the shoulder can be optimized ${ }^{[10]}$. The present study compared arthroscopic repair versus open surgical techniques for the management of recurrent anterior shoulder instability. In present study, group I had 15 males and 10 females and group II had 14 males and 11 females. The mean ROWE pain score at 4 weeks was 3.0 and 3.4 in group I and II respectively, at 6 weeks was 5.4 and 5.0 in group I and II respectively, at 9 weeks was 10.2 and 5.8 in group I and II respectively and at 12 weeks was 10.1 and 9.2 in group I and II respectively. Mukherjee et al. [11] compared the effectiveness i.e. range of motion and incidence of failure 
rates, recurrence and pain of arthroscopic repair versus open surgical techniques for the management of recurrent anterior shoulder instability. 15 cases of anterior shoulder instability treated by arthroscopic method and 15 cases treated by open surgery have been selected for study. About 14 (93.3\%) patients were negative in bony apprehension test in arthroscopic technique. Approximately 15 (93.8\%) patients were positive in bony apprehension test in Open technique. Association between bony apprehension test in two groups was not statistically significant.

We found that mean ASES pain score at 4 weeks was 2.6 and 1.3 in group I and II respectively, at 6 weeks was 4.3 and 2.5 in group I and II respectively, at 9 weeks was 2.8 and 2.0 in group I and II respectively and at 12 weeks was 3.2 and 3.0 in group I and II respectively. Kralinger et al. ${ }^{[12]}$ noted that age between twenty one and thirty years was at risk factor for recurrence in a retrospective series of 180 patients.

\section{Conclusion}

Authors found that both techniques are equally effective in the management of cases of recurrent anterior shoulder instability.

\section{References}

1. DeFroda S, Bokshan S, Stern E, Sullivan K, Owens BD. Arthroscopic Bankart Repair for the Management of Anterior Shoulder Instability: Indications and Outcomes. Curr Rev Musculoskelet Med 2017;10(4):442-51.

2. Kazár B, Relovszky E. Prognosis of Primary Dislocation of the Shoulder. Acta Orthop Scand 1969;40(2):216-24.

3. Godin J, Sekiya JK. Systematic Review of Arthroscopic Versus Open Repair for Recurrent Anterior Shoulder Dislocations. Sports Health 2011;3(4):396-404.

4. Rowe CR, Sakellarides HT. Factors related to recurrences of anterior dislocations of the shoulder. Clin Orthop 1961;20:40-8.

5. Salomonsson B, Jonsson U, Abbaszadegan H, Halvorsen D. Randomized study between capsular shift with bankart repair and puttiplatt. Early results. J Shoulder Elbow Surg 1996;5(2):55.

6. Simonet WT, Melton LJ, Cofield RH, Ilstrup DM. Incidence of Anterior Shoulder Dislocation in Olmsted County, Minnesota. Clin Orthop Relat Res 1984;(186):186-91.

7. Lenters TR, Franta AK, Wolf FM, Leopold SS, Matsen FA. Arthroscopic compared with open repairs for recurrent anterior shoulder instability. A systematic review and meta-analysis of the literature. J Bone Joint Surg Am 2007;89(2):244-54.

8. Paganani MJ, Dome DC. Surgical treatment of traumatic anterior shoulder instability in American football players. J Bone Joint Surg Am 2002;84(5):711-5.

9. Bartl C, Schumann K, Paul J, Vogt S, Imhoff AB. Arthroscopic Capsulolabral Revision Repair for Recurrent Anterior Shoulder Instability. Am J Sports Med 2011;39(3):511-8.

10. Bartl C, Imhoff AB. Arthroscopic Capsulolabral Revision Repair for Recurrent Anterior Shoulder Instability. JBJS Essent Surg Tech 2012;2(1):2.

11. Mukherjee S, Bhattacharya A, Mishra HN, Bhatta R, Saha S. Comparative study between open and arthroscopic surgical techniques in the management of recurrent anterior instability of the shoulder. Indian Journal of Orthopaedics Surgery 2020;6(4):283-91.

12. Kralinger FS, Golser K, Wischatta R, Wambacher M,
Sperner G. Predicting Recurrence after Primary Anterior Shoulder Dislocation. Am J Sports Med 2002;30(1):11620. 